\title{
3 Research Square

\section{Carbon Microsphere From Postconsumer Soft Drink Bottles and Their Impact On Plant Growth Study of Cicer Arietinum}

Naba Kumar Mondal ( $\square$ nkmenvbu@gmail.com )

University of Burdwan https://orcid.org/0000-0002-1554-1390

Papiya Singha

The University of Burdwan

Kamalesh Sen

The University of Burdwan

Arghadip Mondal

The University of Burdwan

Priyanka Debnath

The University of Burdwan

Anupam Mondal

The University of Burdwan

\section{Research Article}

Keywords: PET plastics, Carbon microsphere, Germination, Biochemical analysis

Posted Date: October 29th, 2021

DOI: https://doi.org/10.21203/rs.3.rs-1016392/v1

License: (9) (i) This work is licensed under a Creative Commons Attribution 4.0 International License.

Read Full License 


\section{Abstract}

Present work is highlighted on the conversion of waste PET plastics to carbon nanosphere, their characterization by SEM-EDX, XRD and FTIR and finally their application in the field of germination of Cicer arietinum and biochemical analysis. SEM and XRD results revealed that PET plastic are comfortably converted to carbon microsphere with a diameter ranges between 2-8 $\mu \mathrm{m}$ with amorphous nature and FTIR study suggested that the existence of aromatic $\mathrm{C}-\mathrm{H}$ and aromatic ring along with carbonyl groups. Root morphology suggested that both root length and seminal root number gradually decrease with increasing carbon microsphere dose. Biochemical results revealed that the level of proline, catalase and MDA levels significantly $(p<0.0001)$ increase with increasing the dose of carbon microsphere. Finally, it can be concluded that lower dose of carbon microsphere could be beneficial for both seed germination and seedling growth, but higher dose may have adverse effect on plant community.

\section{Introduction}

Majority of the waste generated from various plastic products such as synthetic plastics which includes polyethylene, polypropylene, polyvinyl chloride, polystyrene etc. across the globe (Ru et al. 2020; Ksenia et al. 2019). Plastics are used in various purposes including packaging industries (Song et al. 2020; Kankanige and Babel, 2020; Giacovelli et al. 2018). As per the composition, around 15\% plastic waste are present in municipal solid waste (Gopu et al. 2018). However, according to USEPA (2018), plastic containers and packaging are the major portion of municipal solid waste which constitute about $29.7 \%$. Plastics are high molecular weight carbon-carbon polymer and it is absolutely non-polar, hydrophobic and non-biodegradable in nature (Zhang et al. 2020). Various plastics products, plastic carry bags, pet water bottles etc. are serious for natural environment because of their degraded products which directly or indirectly impacted on both aquatic and terrestrial ecosystem (Altalhi et al. 2013).

For conversion of plastic materials to a valuable products is the only way to solve the environmental pollution problem as well as economic benefits (Zhang et al. 2021; Choma et al. 2015). Waste plastic can be converted to various carbonaceous products including carbon based nanoparticles (Kharissova et al. 2021; Liu et al. 2020; Altalhi et al. 2013). This type of waste materials transformation to a valuable products leads to the reduction of pollution burden as well as economic benefits. Previous researchers (Altalhi et al. 2013; Altalhi et al. 2011) highlighted that non-degradable plastic bags can be connected to multi-walled carbon nanotube (MwCNTs).

Polyethylene terephthalate is a polymeric form of ethylene terephthalate. It is absolutely a nonpolar polymer. With good mechanical barrier and optical properties. Moreover, its chemical inertness is possibly due to presence of high amount of aromatic substance. Annual production rate of this polymer is greater than 56 million tons (Saxena, 2016) and it is also reported that the total production of plastics will reach to 26000 million tons by 2050 (Lennstedt and Eklov, 2016; Geyer et al. 2017). In review of the increasing environmental awareness, recycling remains the most viable option for the treatment of waste PET. 
The current practice of plastic waste disposal includes incineration and landfilling, including physical and chemical recycling (Chen et al. 2021). However, landfilling is the most accepted techniques among the developing countries (Ru et al. 2020). Similarly, incineration is also a reliable technique. But both landfilling and incineration of plastic waste leads to environmental pollution. Therefore, recycling of waste plastics through greener technique will be the most viable option. Cursory review of literature revealed that some specific microorganism have tremendous power to degrade synthetic plastics through secretion of various enzymes (Ru et al. 2020). However, plastic waste can be degrade by using nanoparticles also (David et al. 2020; Maity and kumar, 2016; Mallakpour and Javadpour, 2016). Previous report also highlighted that plastic polymer can be converted to valuable carbon based materials (Berkmans et al. 2014; Altalhi et al. 2013; Cleetus et al. 2013).

Extensive application of nanomaterials in various fields led to the accumulation of such materials in different compartments of the ecosystem. Therefore, it is extremely important to understand the ultimate fate, migration and impact of such materials on the different compartment of the environment. Keeping in mind the above fact the synthetic plastic waste may be considered as a precursors of carbon source. The ubiquitous polymers such as polyethylene terephthalate is used as a valuable carbon source through thermal cracking and same is used for germination of Cicer arietinum seeds and both morphophysiology and biochemical analysis were performed in laboratory settings. As per our current knowledge, this is the first report of plastic waste origin carbon microsphere (CMS) on plant community.

\section{Materials And Methods}

\section{Preparation of carbon microsphere}

After collection of waste PET plastic bottles from nearby restaurant. Then thoroughly washed with soap water to remove any grease or dirt. Then the bottle was cut into small piceses $(2 \mathrm{~mm})$. About $2.0 \mathrm{~g}$ small pices of plastic was taken in an air-tight stainless steel container without any catalyst. Then the container put into muffle furnace and heat the materials at $800^{\circ} \mathrm{C}$ for $1 \mathrm{~h}$. After overnight cooling, the material was grinded by mechanical grinder and kept in an airtight container.

\section{Characterization of carbon microsphere}

The prepared carbon microsphere were characterized by various analytical tools. Initially, small amount of sample was send for SEM-EDX study. SEM analyzer (HITACHI, S-530, Scanning Electron Microscope and ELKO Engineering) at an accelerating voltage of $20.0 \mathrm{kV}$ was used. The Fourier transform infrared (FTIR) study was carried out for identification of various functional groups associated with carbon microsphere by using FTIR (Cary 630, Agilent Technology).

\section{Design of experimental set up}

Present experiment is conducted in the Environmental Chemistry Laboratory, Department of Environmental science, the University of Burdwan, Burdwan, W.B. Three main concentrations of CMS viz, control $(0 \mathrm{mg} / \mathrm{L}), 100,200$ and $500 \mathrm{mg} / \mathrm{L}$ were used for the treatment of $C$. arietinum seeds. Before 
adding CMS, seeds were sterilized with $1 \%$ sodium hypochlorite solution for one minute followed by washing with double distilled water. Wet Whatman No. 1 filter paper was placed in Petriplate (diameter 90 $\mathrm{mm}$ ) and sterilized seeds were placed on it and proper cover with lid and incubate at room temperature $\left(28 \pm 2^{\circ} \mathrm{C}\right)$. Carbon microsphere solution $(10 \mathrm{~mL})$ was added in each Petriplate after proper sonication in two days interval. Each treatment was replicated thrice following complete randomized design. The entire experimental growth period was 15 days. All the growth and biochemical parameters were measured and presented in graphical and tabular form.

\section{Germination, root and shoot length measurement}

Percentage germination was calculated in three different incubation period $(24,32$ and $40 \mathrm{~h})$ until maximum germination was observed. Following formula was used for calculation of germination:

Germination $(\%)=\frac{(\text { No. of seeds germinated })}{(\text { Total no. of seeds taken })} \times 100$

At the end of experimental period, both control and treated plants was sacrificed for the measurement of root and shoot length by using meter scale, white paper and ordinary microscope.

\section{Fresh and dry biomass}

Fresh weight of both roots and shoots were measured after through washing of harvested plants and tissue paper was used to soaking the water and weighing by digital balance (Sartorious BSA124 S). Similarly, both roots and shoots were placed in Borosil made Petridish and heated in hot air oven at $70{ }^{\circ} \mathrm{C}$ for 3 days and final weight was taken by digital balance.

\section{Estimation of amino acid, protein and carbohydrate}

Amino acid was measured by following the standard protocol (Moore and William, 1954). Similarly, carbohydrate was estimated by anthrone method (McCready et al. 1950). The protein content in both control and treated plant samples were measured by the method as proposed by Lowry et al. (1951). All these parameters was calculates by using standard curve (Mondal, 2017).

\section{Estimation of enzymatic and non-enzymatic antioxidants}

\section{Catalase activity:}

The enzymatic antioxidant was measured by following the method of Sinha (1972) and the activity was expressed as $\mu \mathrm{m} \mathrm{H}_{2} \mathrm{O}_{2} / \mathrm{g}$ protein/ min (Tanase et al. 2013).

\section{Ascorbic acid}

The non-enzymatic antioxidant, ascorbic acid content was measured according to the protocol described by Liang et al. (2016).

\section{MDA level}


MDA was measured from leaf sample $(0.1 \mathrm{mg})$ of $C$. arietinum. Initially leaves were homogenized with 10 $\mathrm{ml} 0.1 \%(\mathrm{w} / \mathrm{v})$ tricholoacetic acid followed by centrifuged at $15000 \times \mathrm{g}\left(4^{\circ} \mathrm{C}\right)$ for $10 \mathrm{~min}$. Then $1 \mathrm{ml}$ supernatant was mixed with $4 \mathrm{~mL} 0.5 \%$ thiobarbutric acid and incubated at $95{ }^{\circ} \mathrm{C}$ for $30 \mathrm{~min}$. Then the reaction was terminated by cooling (ice) and the absorbance was read at 532 and $600 \mathrm{~nm}$ (Heath and Packer, 1968).

\section{Evaluation of cell death}

The cell death of $C$. arietinum roots were examined by Baker and Mock (1994). Measurement of ion leakage from root (Mondal 2017). The percent injury of the membrane was calculated by using the formula (Eq. 2). The electrolytic leakage of control and treated plant roots were used for the measurement of conductivity by following the method Valentoric et al. (2006) with some modification. The conductivity was measured by portable conductivity meter (Systronic 304).

$$
R I L(\%)=\frac{E C_{1}}{E C_{2}} \times 100
$$

Where, $\mathrm{RIL}=$ Root ion leakage $; \mathrm{EC}_{1}$ and $\mathrm{EC}_{2}$ are the electrical conductivity at $25-30{ }^{\circ} \mathrm{C}$ after shaking for $24 \mathrm{~h}$ and autoclaved at $120^{\circ} \mathrm{C}$ for $20 \mathrm{~min}$ and cooled at $25^{\circ} \mathrm{C}$, respectively.

\section{Statistical analysis}

One way ANOVA followed by Tukey's post hoc test was used to test significance $(p<0.05)$ of data i.e. percentage of germination, root and shoot length, fresh and dry weight of roots and shoots, pigment level (chl ' $a$ ', chl 'b', total chl and carotenoid), carbohydrates, protein, amino acid, ascorbic acid, catalase, proline and MDA content. Error bars indicates the standard error at $5 \%$ level of significance.

\section{Results And Discussion}

\section{SEM-EDX study}

Scanning electron micrograph study along with EDX was used to evaluate the morphology of PET carbon microsphere and it is presented in Figure 1. From the Figure 1, it is clearly demonstrated that PET plastic carbon microsphere are uniformly sphere with diameter 2-8 $\mu \mathrm{m}$. On the other hand, EDX signature revealed the existence of carbon. Almost similar result was reported by Wei et al. (2011) for the thermal dissociation of PET in a supercritical- $\mathrm{CO}_{2}$ system at $500^{\circ} \mathrm{C}$ for $3 \mathrm{~h}$. They also reported that perfect spherical carbon with $1-5 \mu \mathrm{m}$ sized can be achieved at $600^{\circ} \mathrm{C}$ and these carbon spheres are smoother surface. Present study structurally and morphologically exactly same as reported by Wei et al. (2011). Very minute observation also revealed that the existence of small particles on the surface of the majority of the spheres. These small particles on the spheres are may be the carbon pieces (Wei et al. 2011).

\section{FTIR study}


Fourier transform infrared spectroscopy is an important analytical study by which important functional groups associated with nanoparticles can be identified (Bhaumik et al. 2017). Figure 2a clearly

demonstrated the FTIR of PET plastic carbon microsphere. The sharp peaks at $3166 \mathrm{~cm}^{-1}$ and $1440 \mathrm{~cm}^{-1}$ are due to aromatic $\mathrm{C}-\mathrm{H}$ and aromatic ring, respectively (Wei et al. 2011). Another strong peak was observed at $1705 \mathrm{~cm}^{-1}$ which also indicate the presence of $-\mathrm{C}=0$ vibration of carbonyl group (Fig. 2a). Present findings showed good agreement with the findings of Wei et al. (2011) and $\mathrm{Ng}$ et al. (2018).

\section{XRD study}

The XRD diagram of the PET plastic origin carbon microsphere sample is shown in Fig. $2 \mathrm{~b}$. The broad diffraction peaks of this XRD at 22.97 and $42.782 \theta$ which correspond to the (002) and (100) reflections, respectively for graphene. This diffraction peaks is very similar to amorphous graphite like carbons (Zhang et al. 2016; Sergiienko et al. 2009). Moreover, the broad (002) peak, in particular, encompasses diffuse sets of inter-layer distances which, on average, are larger than those in crystalline graphite (typically $0.344-0.355 \mathrm{~nm}$ ).

\section{Germination study}

Germination of Cicer aritenium was conducted (Eq. 1) under different doses of carbon microsphere (Fig. $S 1)$. The entire germination was studied in three different time intervals ( $24 \mathrm{~h}, 32 \mathrm{~h}$ and $40 \mathrm{~h}$ ) and results highlighted in Fig. S1. From the Fig. S1, it is clear that only $\mathrm{T}_{3}$ treatment showed higher germination $(53.33 \%)$ with respect to control $\left(T_{1} 50 \%\right)$ during $24 \mathrm{~h}$ of incubation and no statistical difference $(\mathrm{p}<$ 0.069 ) was observed. Almost similar nonsignificant $(p<0.069)$ of germination pattern of Cicer aritenium was recorded during $32 \mathrm{~h}$ of incubation. However, during $40 \mathrm{~h}$ actual germination picture was recorded and results revealed that with increasing CMS dose, germination increased and maximum germination was recorded at $\mathrm{T}_{4}$ treatment $(96.67 \%)$, but no statistical significant difference $(\mathrm{p}<0.502)$ was observed. These results are not strictly agreed with previous study (Magrabosco et al. 2020) where, carbon nanotube (bionic carbon microsphere) does not greatly influence the germination. However, Nair et al. (2012) successfully addressed that carbon nanostructure significantly increased the water content in seeds of rice during germination compared to control.

\section{Root and shoot length}

The variation of root and shoot length was recorded under difficult treatment conditions at 10 and 15 days interval (Fig. S 2 and S 3). After 10 days, root length of all treatments showed significantly ( $p<$ 0.001 ) different from control (Fig. 3). Similar, significant different $(p<0.039)$ in root length was also recorded after 15 days (Fig. 3). On the other hand, the variation of shoot length in both time intervals (10 and 15 days) showed non-significant variation (Fig. 3). Present results showed good agreement with the earlier study as reported by Haghighi et al. (2014) who demonstrated the significant increment of root length of tomato under higher concentration $(40 \mathrm{mg} / \mathrm{L})$ of carbon nanotubes. Similarly, Jiang et al. (2014) showed the enhancement of both root and shoot of rice with the treatment of carbon nanotubes at $100 \mu \mathrm{g} / \mathrm{mL}$. Therefore, those results clearly demonstrated that PET plastic origin carbon microsphere has remarkable impact on root length over shoot length of cicer arietinum $\mathrm{L}$. 


\section{Root morphology}

The morphology of root was assessed under treatment condition in comparison to control and photograph was presented in Figure S 4. From the figure S4 it is revealed that both root length and seminal root number decrease with increasing PET plastic origin carbon microsphere. Moreover, the overall health of the root is also deteriorated with increasing the dose of carbon microsphere dose. Almost similar observation of root morphology was demonstrated by Hajra and Mondal (2017) under treatment with $\mathrm{ZnO}$ on Cicer arietinum L.

\section{Fresh and dry biomass}

Fresh and dry biomass of shoot and root are presented in Table 1. The results revealed that highest fresh weight at treatment ${ }_{\mathrm{T}_{3}}$ compared ${ }_{\text {to }}$ control. However, highest root weight was recorded at treatment $\mathrm{T}_{4}$ with respect to control. Similar non-significant results were recorded for dry mass of both root $(p<0.625)$ and shoot $(p<0.417)$. Therefore, present finding suggest that fresh weight is accelerated than dry weight. Almost similar improvement in fresh weight under treatment of carbon nanotubes on radish (Haghighi et al. (2014) and switchgress (Pandey et al. 2018) was reported.

Table 1

Variation of fresh and dry weight of roots and shoots of Cicer arietinum under different treatments.

\begin{tabular}{|lllll|}
\hline \multirow{2}{*}{ Treatment } & \multicolumn{2}{l}{ Fresh weight (g) } & \multicolumn{2}{l|}{ Dry weight (g) } \\
\cline { 2 - 5 } & Root & Shoot & Root & Shoot \\
\hline T1 & 0.943 & 1.057 & 0.097 & 0.087 \\
\hline T2 & 0.770 & 0.933 & 0.073 & 0.063 \\
\hline T3 & 0.780 & 1,267 & 0.100 & 0.060 \\
\hline T4 & 0.957 & 1.230 & 0.101 & 0.074 \\
\hline ANOVA (F) & 1.210 & 1.695 & 0.614 & 1.063 \\
\hline P value & $<0.367$ & $<0.245$ & $<0.625$ & $<0.417$ \\
\hline
\end{tabular}

\section{Photosynthetic pigment}

In photosynthesis I and II, chlorophyll played vital role for communication of light energy to chemical energy through absorption of visible light (Komenda and Sobotka, 2019). Pigment levels (chl 'a', chl 'b', total chl and carotenoid) under different doses of plastic carbon microsphere were measured and results depicted in Fig. 4. From the Fig. 4, it is clear that all the pigments gradually increased with increasing concentration of nanocomposite dose. One way ANOVA analysis revealed that the chlorophyll 'a' levels under all treatments are statistically significant $(p<0.001)$ than control and higher level of cholorophyll ' $a$ ' was recorded in treatment $T_{4}$. Similarly, chlorophyll ' $b$ ' level also increased with increasing the concentration of nanocomposite dose. However, treatment wise variation of chlorophyll 'b' not 
statistically significant. But one way ANOVA study indicate that the total chlorophyll level is statistically significant $(p<0.001)$ among different treatments. Almost similar statistical significant $(p<0.001)$ difference among different treatments was recorded for carotenoid also. This pigment level also showed dose dependent, i.e. level of carotenoid increase with increasing the concentration of carbon microsphere dose. Almost similar results of enhancement of carotenoid was reported by Siddique et al. (2019) with application of graphene oxide in carrot seedling. Very recently, Gonzalez-Garcia et al. (2019) demonstrated the application of graphene and carbon nanotube on tomato seedlings leads to increase chlorophyll content (chl ' $a$ ', chl ' $b$ ', total chl). However, they also suggested that the level of chlorophyll is higher in graphene application than carbon nanotube.

\section{Carbohydrate, protein and ascorbic acid level}

Carbohydrate is an indispensable component in our daily diet (Mehmood and Murtaza, 2017). The level of carbohydrate was recorded in higher concentration $\left(T_{4}\right)$ (Fig. 5). One way ANOVA results suggested a statistical significant difference $(p<0.0001)$ among the different treatments. Almost similar dose dependent results was reported by Mehmood and Murtaza (2017).

Similarly protein level was assessed under different concentration of carbon microsphere (Fig. 5). Results also indicates that with increasing concentration, protein level decrease. However, variation of protein under different treatments are statistically significant $(p<0.037)$. Mehmood and Murtaza (2017) concluded in their research that biosynthesis of silver nanoparticles can enhance the protein level. Very recently, Gonzalez-Garcia et al. (2019) also endorse the same positive effect of carbon nanoparticles application on protein level in tomato seedlings. However, almost opposite results was reported by Mehrian et al. (2015). They highlighted that, with increasing the concentration of silver nanoparticles on tomato plants, total soluble protein level significantly decreased.

\section{Ascorbic acid analysis}

Level of ascorbic acid under different concentrations of carbon microsphere is presented in Fig. 5. Higher level of ascorbic acid was recorded in lower concentration $\left(T_{2}\right)$ and it is significantly $(p<0.0001)$ higher control. However, in higher concentration, ascorbic acid level reduced or reach at the level of control. This result indicate that lower dose of nanocomposite can increase ascorbate-glutathion cycle (Sharma et al. 2016). That means it improves osmoregulation, enhancement of nutrient use efficiency and photosynthetic performance (Hasanuzzaman et al. 2019). Present result is in agreement with the earlier study reported by Gonzalez-Garcia et al. (2019). They reported that application of carbon nanomaterials can trigger the level of ascorbic acid in tomato seedlings.

\section{Amino acid, proline and MDA level}

Present study also assessed the amino acid level under different treatment conditions. From the present finding, it has been found that amino acid level gradually increase with increasing treatment concentration. (Table 2). One way ANOVA analysis revealed that there is significant $(p<0.0001)$ variation 
among different treatments (Table 2). Present study results are very much consistent with the earlier findings as reported by Mehrian et al. (2015).

Table 2

Variation of RIL, MDA, proline, amino acid and catalase under different treatments.

\begin{tabular}{|llllll|}
\hline Treatments & $\begin{array}{l}\text { RIL } \\
(\%)\end{array}$ & $\begin{array}{l}\text { MDA } \\
(\%)\end{array}$ & $\begin{array}{l}\text { Proline } \\
(\mu \mathrm{g} / \mathrm{g})\end{array}$ & $\begin{array}{l}\text { Amino acid } \\
(\mu \mathrm{g} / \mathrm{g})\end{array}$ & Catalase $(\mu \mathrm{M} / \mathrm{min})$ \\
\hline T1 & $25.267^{\mathrm{d}}$ & $0.017^{\mathrm{d}}$ & $0.507^{\mathrm{b}}$ & $0.243^{\mathrm{c}}$ & $1.500^{\mathrm{d}}$ \\
\hline T2 & $28.567^{\mathrm{c}}$ & $0.023^{\mathrm{c}}$ & $0.380^{\mathrm{c}}$ & $0.267^{\mathrm{d}}$ & $2.010^{\mathrm{c}}$ \\
\hline T3 & $33.767^{\mathrm{b}}$ & $0.050^{\mathrm{b}}$ & $0.477^{\mathrm{b}}$ & $0.483^{\mathrm{b}}$ & $2.327^{\mathrm{b}}$ \\
\hline T4 & $53.133^{\mathrm{a}}$ & $0.094^{\mathrm{a}}$ & $1,307^{\mathrm{a}}$ & $0.727^{\mathrm{a}}$ & $2.477^{\mathrm{a}}$ \\
\hline ANOVA (F) & 2042.32 & 996.94 & 1302.29 & 225.173 & 27.846 \\
\hline P value & $<0.0001$ & $<0.0001$ & $<0.0001$ & $<0.0001$ & $<0.0001$ \\
\hline RIL: Root ion leakage; MDA: Malondialdehyde & & \\
\hline
\end{tabular}

Proline is multifunctional amino acid which is also a good plant stress (biotic or abiotic) indicator (Senthil Kumar and Mysore, 2012). Proline level under treatment of various doses of PET plastic carbon microsphere leads to gradual increase of proline levels (Table 2). These data clearly suggested that under treatment of carbon microsphere, some sort of stress is generated inside the plant. One-way ANOVA (< 0.0001 ) clearly endorse the same. During stress condition, the enhancement of proline level is due to proper maintenance of osmotic balance, reduction of ROs, stabilization of membrane (Ahanger and Agarwal, 2017) and protein also proper maintenance of redox potential (Wahid et al. 2007). Shabnam and Kim (2018) also recorded the similar enhancement of proline level in mung bean under the exposure of nano aluminium.

Generation of ROS leads to the membrane damage which is again assessed through estimation of MDA level (Huang et al. 2018; Benson and Brenner, 2004). In this study, MDA level was assessed under different treatment conditions and results are depicted in Figure 5. One way ANOVA results revealed that, there is strong statistical significant $(p<0.0001)$ in MDA exists among different treatments (Table 2$)$. Results also suggests that, MDA level increase with increasing concentration i.e. absolutely dose dependent variation was recorded. This enhancement of MDA level in the form of lipid peroxidation leads to the generation of oxidative stress under higher dose of carbon microsphere (Debnath et al. 2020). Shabnam and Kim (2018) highlighted that application of nano alumina on mungbean seedlings leads to enhancement of MDA level. Similarly, Souza et al. (2019) highlighted that the up regulation of MDA in Lemna minor under treatment of iron oxide nanoparticles.

\section{Catalase}


Antioxidant defense system of plants can function as enzymatic or non-enzymatic activity towards control on reactive oxygen species. Present outcome highlighted in Table 2 where it is clearly revealed that with increasing CMS dose, catalase level increased statistically $(p<0001)$. Almost opposite results was reported by Shabnam and Kim (2018). They recorded that, nano aluminium has no impact on antioxidant enzyme including catalase.

\section{Cell death}

The assessment of cell death was measured through the estimation of root ion leakage (Mishra et al. 2021) and results are depicted in Table 2. From the experimental results it has been found that the percentage of root ion leakage significantly $(p<0.0001)$ increase with increasing CMS dose. This may be attributed by the fact that with increasing the CMS dose, generation of reactive oxygen species (ROS) was increased (Begum et al. 2012). Moreover, this ROS accumulation not only enhanced the electrolyte leakage, but also causes cell death (Tan et al. 2009; Kawai-Yanada et al. 2004).

\section{Conclusion}

Present finding highlighted that commercial PET bottle can be transformed into carbon microsphere which is confirmed from Scanning Electron Micrograph-Energy Dispersive X-ray analysis (SEM-EDX) and Fourier Transform Infrared Spectroscopy (FTIR). Moreover, PET plastic origin carbon microsphere was applied on the germination and seedling growth of Cicer arietinum. The germination result revealed that within $30 \mathrm{~h}$, only lower treatments ( $\mathrm{T} 1$ and $\mathrm{T} 2$ ) along with control was fully germinated and after $40 \mathrm{~h}$, all treatments exhibited complete germination. The root and shoot length was recorded maximum at minimum dose. On the other hand, biochemical results revealed that maximum chlorophyll at intermediate concentration (T3). Root morphology study suggested that both root length and seminal root number gradually decrease with increasing carbon microsphere dose. Biochemical results revealed that the level of carbohydrate, amino acid and protein are highest in treatment T3 compared to control. On the other hand, proline, catalase and MDA levels significantly $(p<0.0001)$ increase with increasing the dose of carbon microsphere. Therefore, finally, it can be concluded that PET origin carbon microsphere could be potentially applied for priming of seeds including horticultural crops.

\section{Declarations}

\section{Acknowledgements}

The authors express there sincere thanks to all the faculty members including technical staff of the Department of Environmental Science, The University of Burdwan, for their moral support. Authors also like to thank to the technical staff of University Instrumentation Centre (USIC), The University of Burdwan, for their active help with sample characterization. This work was supported by the Unversity of Burdwan in the form of M.Sc. dissertation work (M.Sc./Diss/ 2019-2020(1)). Authors also extend their thanks to WBDST-BOOST, Govt. of West Bengal (39/WBBDC/1p-2/2013,dt: 25.03.2015) and DST-FIST, Govt of India (SR/FST/ESI-141/2015, dt: 30.09.2019) for providing necessary funds. 


\section{Declaration of competing interest}

The authors declare that they have no known competing financial interests

\section{References}

1. Ahanger MA, Agarwal RM (2017) Potassium up-regulates antioxidant metabolism and alleviates growth inhibition under water and osmotic stress in wheat (Triticum aestivum L). Protoplasma 254: 1471-1486. https://doi.org/10.1007/s00709-016-1037-0

2. Altalhi T, Ginic-Markovic M, Han N, Clarke S, Losic D (2011) Synthesis of carbon nanotube (CNT) composite membranes. Membranes 1: 37-47. https://doi.org/10.3390/membranes1010037

3. Altalhi T, Kumeria T, Santos A, Losic D (2013) Synthesis of well-organised carbon nanotube membranes from non-degradable plastic bags with tuneable molecular transport: towards nanotechnological recycling. Carbon 63:423-433. https://doi.org/10.1016/j.carbon.2013.07.003

4. Baker CJ, Mock NM (1994) An improved method for monitoring cell death in cell suspension and leaf disc assays using Evans blue. Plant Cell Tissue Organ Cult 39: 7-

12. https://doi.org/10.1007/BF00037585

5. Bazargan A, McKay G, (2012) A review - synthesis of carbon nanotubes from waste plastics. Chem Eng J 195-196: 377-391. https://doi.org/10.1016/j.cej.2012.03.077

6. Begum p, Ikhtiari R, Fugetsu B, Matsuok M, Akasak T, Watari F (2012) Phytotoxicity of multi-walled carbon nanotubes assessed by selected plant species in the seedling stage. Appl. Surface. Sci. 262: 120-124. https://doi.org/10.1016/j.apsusc.2012.03.028

7. Benson EE, Bremner D (2004) Oxidative stress in the frozen plant: a free radical point of view. In 'Life in the frozen state'. (Eds BJ Fuller, NLane,EE Benson) 205-242. (CRC Press: Boca Raton, FL, USA).

8. Berkmans AJ, Jagannatham M, Priyanka S, Haridoss, P (2014) Synthesis of branched, nano channeled, Ultrafine and nanocarbon tubes from PET wastes using the arc discharge method. Waste from PET wastes using the arc discharge method. J Waste Manag DOI 10.2016/j.wasman.2014.07.004.

9. Bhaumik R, Mondal NK, Chattoraj S (2017) An optimization study for defluoridation from synthetic fluoride solution using scale of Indian major carp Catla (Catla catla): an unconventional biosorbent. J Fluorine Chem 195: 57-59. https://doi.org/10.1016/j.jfluchem.2017.01.015

10. Chen Y, Awasthi AK, Wei F, Tan Q, Li J (2021) Single-use plastics: Production, usage, disposal, and adverse impacts. Sci Total Environ 752:141772. https://doi.org/10.1016/j.scitotenv.2020.141772

11. Choma J, Marszewski M, Osuchowski L, Jagiello J, Dziura A, Jaroniec M (2015) Adsorption Properties of Activated Carbons Prepared from Waste CDs and DVDs. Sustainable Chem Eng 3: 733742. https://doi.org/10.1021/acssuschemeng.5b00036

12. Cleetus $C$, Thomas $S$, Varghese $S$ (2013) Synthesis of petroleum based fuel from waste plastics and performance analysis in a $\mathrm{Cl}$ engine. J Energy 1-10. https://doi.org/10.1155/2013/608797 
13. David M, Prakash L, Sangeetha J, et al (2020) Degradation of Plastics Using Nanomaterials. Handbook of Nanomaterials and Nanocomposites for Energy and Environmental Applications 1-13. doi: 10.1007/978-3-030-11155-7_74-1

14. Debnath P, Mondal A, Sen K, Mishra D, Mondal NK, (2020) Genotoxicity study of nano Al2O3, TiO2 and $\mathrm{ZnO}$ along with UV-B exposure: An Allium cepa root tip assay. Sci Total Environ 713: 136592. https://doi.org/10.1016/j.scitotenv.2020.136592

15. Geyer R. Jambeck J, Law KL, (2017) Production, use and taste of all plastics ever made. Sci Adv 3(7) e:700782. doi:10.1126/sciadv.1700782.

16. González-García Y, López-Vargas ER, Cadenas-Pliego G, Benavides-Mendoza A, González-Morales S, Robledo-Olivo A, Alpuche-Solís ÁG, Juárez-Maldonado A (2019) Impact of Carbon Nanomaterials on the Antioxidant System of Tomato Seedlings. Int J Mol Sci 20(23):5858. doi: 10.3390/ijms20235858.

17. UNEP-Single-use plastics: A roadmap for sustainability (2018) https://www.unep.org/resources/report/single-use-plastics-roadmap-sustainability

18. Gopu C, Gao L, Volpe M, Fiori L, Goldfarb JL (2018) Valorizing solid waste: waste to energy and activated carbons for water treatment via pyrolysis. J Anal Appl Pyrolysis 133:48-

58. https://doi.org/10.1016/j.jaap.2018.05.002

19. Hajra A, Mondal NK (2017) Effects of $\mathrm{ZnO}$ and $\mathrm{TiO}_{2}$ nanoparticles on germination, biochemical and morphoanatomical attributes of Cicer arietinum. L. Energy Ecol Environ 2:277288. https://doi.org/10.1007/s40974-017-0059-6

20. Haghighi M, Jaime A, Da Silva T (2014) The effect of carbon nanotubes on the seed germination and seedling growth of vegetable species. J Crop Sci Biotech 17(4):201208. https://doi.org/10.1007/s12892-014-0057-6

21. Hasanuzzaman M, Bhuyan MHMB, Anee TI, Parvin K, Nahar K, Mahmud JA, Fujita M (2019) Regulation of Ascorbate-Glutathione Pathway in Mitigating Oxidative Damage in Plants under Abiotic Stress. Antioxidants (Basel) 8(9):384. doi: 10.3390/antiox8090384.

22. Heath RL, Packer L, (1968) Photoperoxidation in Isolated Chloroplasts: I. Kinetics and Stoichiometry of Fatty Acid Peroxidation. Arch Biochem Biophys 125:189-198. doi: 10.1016/0003-9861(68)906541.

23. Huang B, Zhang JM, Chen XL, Xin X, Yin GK, He JJ, Lu XX, Zhou YC (2018) Oxidative damage and antioxidative indicators in $48 \mathrm{~h}$ germinated rice embryos during the vitrification-cryopreservation procedure. Plant Cell Rep 37(9):1325-1342. doi: 10.1007/s00299-018-2315-4.

24. Jiang YM, Hua ZT, Zhao YQ, Liu QD, Wang F, Zhang Q, (2014) The effect of carbon nanotubes on rice seed germination and root growth. In T-C Zhang, ed, Proceedings of the 2012 International Conference on Applied Biotechnology, Lecture Notes in Electrical Engineering 250: 1207-1212.

25. Kankanige D, Babel S (2020) Smaller-sized micro-plastics (MPs) contamination in single-use PET bottled water in Thailand. Sci. Total Environ

717:137232. https://doi.org/10.1016/j.scitotenv.2020.137232 
26. Ksenia JG, Thomas B, Bethanie CA, Birgit G, Pedro Al, Anna L, Heather AL, Maricel M, Daniel S, Leonardo T, Warhurst AM, Munck J, (2019) Overview of known plastic packaging-associated chemicals and their hazards. Sci Total Environ 651:3253-

3268. https://doi.org/10.1016/j.scitotenv.2018.10.015

27. Kawai-Yamada, Ohori M, Uchimiya H (2004) Dissection of Arabidopsis Bax inhibitor-1 suppressing Bax-, hydrogen Y. peroxide-, and salicylic acid-induced cell death. Plant Cell 16: 21-32. https://doi.org/10.1105/tpc.014613

28. Kharissova OV, Torres-Martinez, Myriam LK, Ildusovich B (2021) Handbook of nanomaterials and carbon microsphere for energy and environmental applications. DOI 10.1007/978-3-030-11155-7-741.

29. Komenda J, Sobotka R (2019) Chlorophyll-binding subunits of photosystem I and II: Biosynthesis, chlorophyll incorporation and assembly. Advances in Botanical Research. In book: Metabolism, Structure and Function of Plant Tetrapyrroles: Control Mechanisms of Chlorophyll Biosynthesis and Analysis of Chlorophyll-Binding Proteins 91:195-223.

30. Lennstedt OM, Eklov P (2016) Environmentally relevant concentrations of microplastic particles influence larval fish ecology. Science 352: 1213-1216. DOI: 10.1126/science.aad8828

31. Liang T, Ding H, Wang G, Kang J, Pang H, Lv J (2016) Sulfur decreases cadmium translocation and enhances cadmium tolerance by promoting sulfur assimilation and glutathione metabolism in Brassica chinensis L. Ecotoxicol Environ Saf 124:129-137. doi: 10.1016/j.ecoenv.2015.10.011.

32. Liu X, Wen Y, Chen X, Tang T, Mijowska E (2020) Co-etching effect to convert waste polyethylene terephthalate into hierarchical porous carbon toward excellent capacitive energy storage. Sci. Total Environ. 723: 138055. doi.org/10.1016/j.scitotenv.2020.138055

33. Lowry O.H, Rosenbrough NJ, Farr Al, Randall RJ (1951) Protein measurement with folin phenol reagent. J. Biol. Chem. 193: 265-275. https://doi.org/10.1016/S0021-9258(19)52451-6

34. Magnabosco G, Pantano MF, Rapino S, Di Giosia M, Valle F, Taxis L, Sparla F, Falini G, Pugno NM, Calvaresi M (2020) A Plant Bioreactor for the Synthesis of Carbon Nanotube Bionic Carbon microsphere. Front Bioeng Biotechnol 8:560349. https://doi.org/10.3389/fbioe.2020.560349

35. Maity P, Kumar S (2016) Controlled biodegradation of polymers using nanoparticles and their application. RSC Advances. DOI 10.1039/C6RA08641A.

36. Mallakpour S, Javadpour M (2016) The potential use of recycled PET bottle in carbon microsphere manufacturing with modified ZnO nanoparticles capped with citric acid: preparation, thermal and morphological characterization. RSC Advances. DOI 10.1039/C5RA27631D.

37. McCready RM, Guygolz J, Silviera V, Owens HS (1950) Determination of Starch and Amylase in Vegetables. Anal Chem 22:1156-1158. https://doi.org/10.1021/ac60045a016

38. Mehmood A, Murtaza G (2017) Impact of biosynthesized silver nanoparticles on protein and carbohydrate contents in seeds of Pisum sativum L. Crop Breed Appl Biotechnol 17(4):334340. https://doi.org/10.1590/1984-70332017v17n4a51 
39. Mehrian SK, Heidari R, Rahmani F (2015) Effect of silver nanoparticles on free amino acids content and antioxidant defense system of tomato plants. Ind J Plant Physiol 20:257263. https://doi.org/10.1007/s40502-015-0171-6

40. Mishra D, Mondal A, Sen K, Debnath P, Mondal NK (2021) A study on the role of Silica nanoparticles in alleviation of fluoride toxicity in rice (Oryza sativa L.) seedlings. Plant Physiol Rep https://doi.org/10.1007/s40502-021-00573-5

41. Mondal NK (2017) Effect of fluoride on photosynthesis, growth and accumulation of four widely cultivated rice (Oryza sativa L.) varieties in India. Ecotoxicol Environ Saf 144:36-44. doi: 10.1016/j.ecoenv.2017.06.009

42. Moore S, Stein WH (1954) A modified ninhydrin reagent for the photometric determination of amino acids and related compounds. J Biol Chem 211:907-913. https://doi.org/10.1016/S00219258(18)71178-2

43. Nair R, Mohamed MS, Gao W, Maekawa T, Yoshida Y, Ajayan PM, Kumar DS (2012) Effect of carbon nanomaterials on the germination and growth of rice plants. J Nanosci Nanotechnol 12(3): 22122220. doi: 10.1166/jnn.2012.5775.

44. Ng SWL, Yilmaz G, Ong WL, Ho GW (2018) One-step activation towards spontaneous etching of hollow and hierarchical porous carbon nanospheres for enhanced pollutant adsorption and energy storage. App Cat B: Environ 220: 533-541. https://doi.org/10.1016/j.apcatb.2017.08.069

45. Pandey K, Lahiani MH, Hicks VK, Hudson MK, Green MJ, Khodakovskaya M (2018) Effects of carbonbased nanomaterials on seed germination, biomass accumulation and salt stress response of bioenergy crops. PLoS One. 13(8): e0202274. https://doi.org/10.1371/journal.pone.0202274.

46. Ru J, Huo Y, Yang Y (2020) Microbial degradation and valorization of plastic wastes. Front. Microbiol. DOI:10.3389/FMICB.2020.00442.

47. Saxena, S (2016) Newly identified bacteria cleans up common plastic. Ars Tectmica.

48. Senthil-kumar M, Mysore KS (2012) Ornithine-delta-aminotransferase and proline dehydrogenase genes play a role in non-host disease resistance by regulating pyrroline-5-carboxylate metabolisminduced hypersensitive response. Plant Cell Environ 35(7):1329-1343. doi: 10.1111/j.13653040.2012.02492.x

49. Sergiienko R, Shibata E, Kim S, et al (2009) Nanographite structures formed during annealing of disordered carbon containing finely-dispersed carbon nanocapsules with iron carbide cores. Carbon 47:1056-1065. doi: 10.1016/j.carbon.2008.12.029

50. Shabnam N, Kim H (2018) Non-toxicity of nano alumina: A case on mung bean seedlings. Ecotoxicol. Environ Saf 15(165): 423-433. doi: 10.1016/j.ecoenv.2018.09.033.

51. Sharma S, Sehrawat A, Deswal R (2016) Asada-Halliwell pathway maintains redox status in Dioscorea alata tuber which helps in germination. Plant Sci 250: 20-29. doi: 10.1016/j.plantsci.2016.05.013.

52. Siddique ZA, Parveen A, Ahmad L, Hashem A (2019) Effects of graphene oxide and zinc oxide nanoparticles on growth, chlorophyll, carotenoids, proline contents and diseases of carrot. Sci Hortic- 
Amsterdam 249:374-382. DOI: 10.1016/j.scienta.2019.01.054

53. Sinha, A.K (1972) Colorimetric assay of catalase. Anal. Biochem 47:389-394. doi: 10.1016/00032697(72)90132-7.

54. Song C, Zhang B, Hao L, Min J, Liu N, Niu R, Gong J, Tang T (2020) Coverting poly (ethylene terephthalate) waste into $\mathrm{N}$-doped porous carbon as $\mathrm{CO}_{2}$ adsorbent and solar steam generator. Green. Energy. Env. doi:10.1016/j.gee.2020.10.002.

55. Souza LRR, Bernardes LE, Barbetta MFS, Silva da Veiga MAM (2019) Iron oxide

56. nanoparticle phytotoxicity to the aquatic plant Lemna minor: effect on reactive oxygen species (ROS) production and chlorophyll a/chlorophyll b ratio. Environ Sci Pollut R 26:24121-24131. https://doi.org/10.1007/s11356-019-05713-x

57. Tan XM, Lin XC, Fugetsu B (2009) Studies on toxicity of multi-walled carbon nanotubes on suspension rice cells. Carbon 47:3479-3487. https://doi.org/10.1016/j.carbon.2009.08.018

58. Tanase C, Volf I, Vantu S, Gradinaru R, Poapa IV (2013) Potential applications of wastes from energy and forestry industry in plant tissue culture. Cellul Chem Technol 47(7):553-563.

59. Wahid A, Gelani S, Ashraf M, Foolad MR (2007) Heat tolerance in plants: an overview. Environ Exp Bot 61(3):199-223. https://doi.org/10.1016/j.envexpbot.2007.05.011

60. USEPA-Advancing Sustainable Materials Management: Facts and Figures Report (2020) https://www.epa.gov/facts-and-figures-about-materials-waste-and-recycling/advancingsustainable-materials-management .

61. Valentoric P, Luxova M, Kolarovic L, Gasparikov O (2006) Effect of osmotic stress on compatible solutes content, membrane stability and water relations in two maize cultivars. Plant Cell Environ 52 (4):186-191.

62. Wei L, Yan N, Chen Q (2011) Converting Poly (ethylene terephthalate) Waste into Carbon Microspheres in a Supercritical $\mathrm{CO}_{2}$ System. Environ Sci Technol 45:534-539. https://doi.org/10.1021/es102431e

63. Zhang H, Zhou Xi-Li, Shao Li-M, Lu F, He P-J (2021) Upcycling of PET waste into methane-rich gas and hierarchical porous carbon for high-performance supercapacitor by autogenic pressure pyrolysis and activation. Sci Total Environ 772:145309. doi.org/10.1016/j.scitotenv.2021.145309

64. Zhang H, Pap S, Taggart MA, Boyd KG, James NA, Gibb SW (2020) A review of the potential utilization of plastic waste as adsorbent for removal of hazardous priority contaminants from aqueous environments. Environ Pollut 258:113698. https://doi.org/10.1016/j.envpol.2019.113698

65. Zhang J, X Wang, G Qi, B Li, Z Song, H Jiang, X Zhang, J Qiao (2016) A novel N-doped porous carbon microsphere composed of hollow carbon nanospheres. Carbon 96:864-870. doi:10.1016/j.carbon.2015.10.045

\section{Figures}




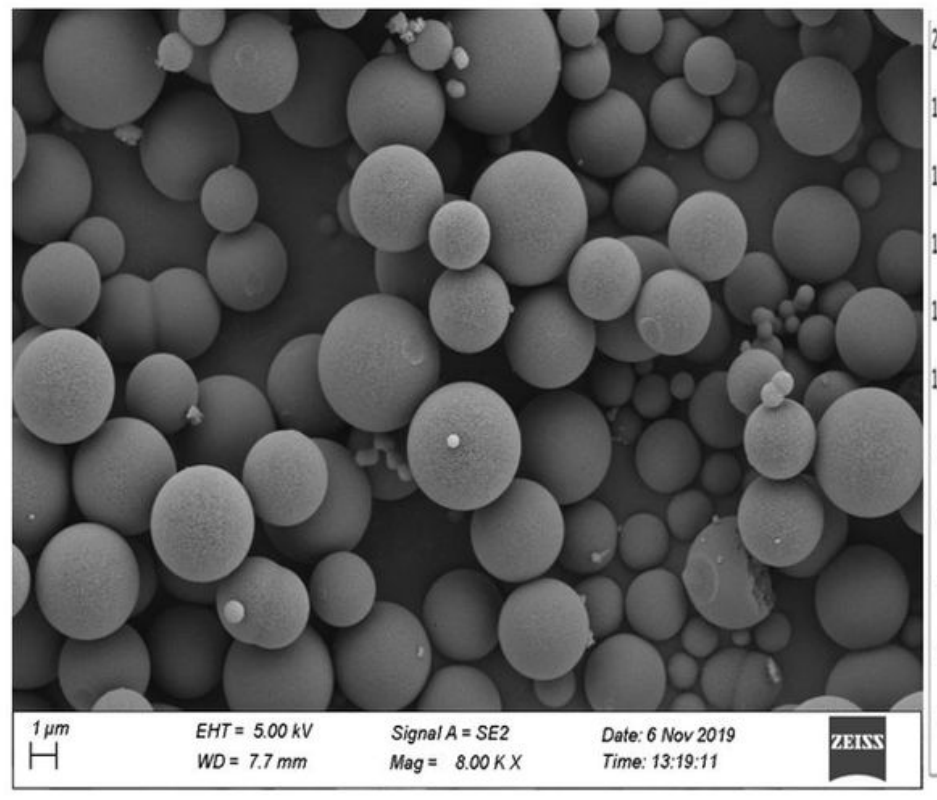

A

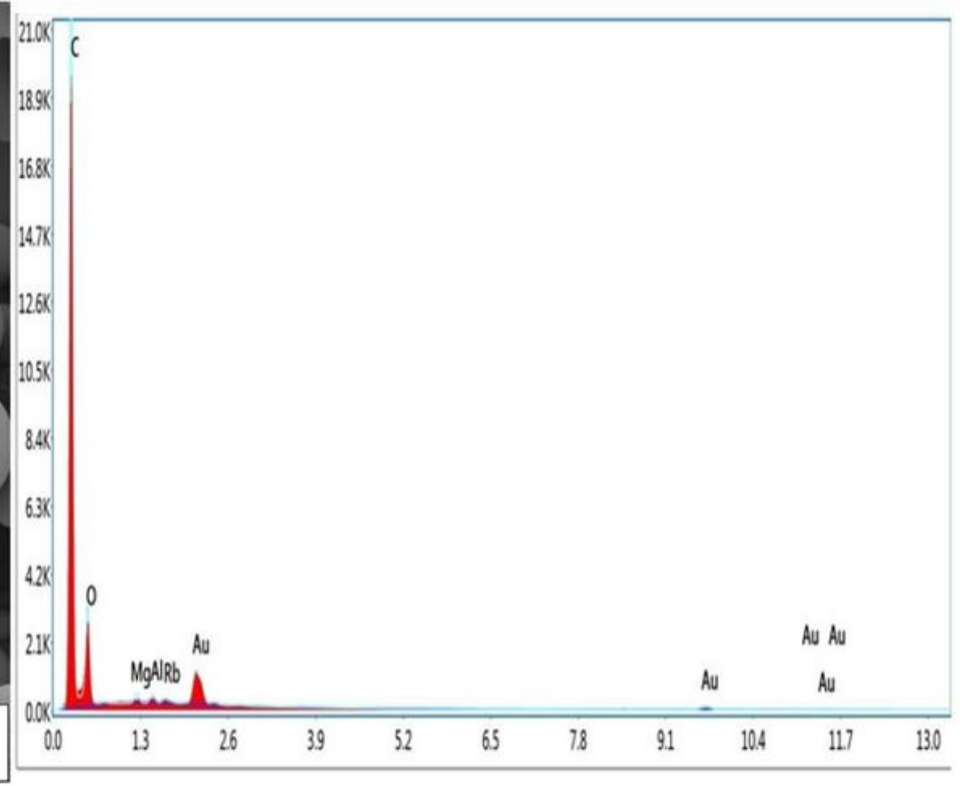

B

\section{Figure 1}

A. SEM and B. EDX image of synthesized carbon microsphere.
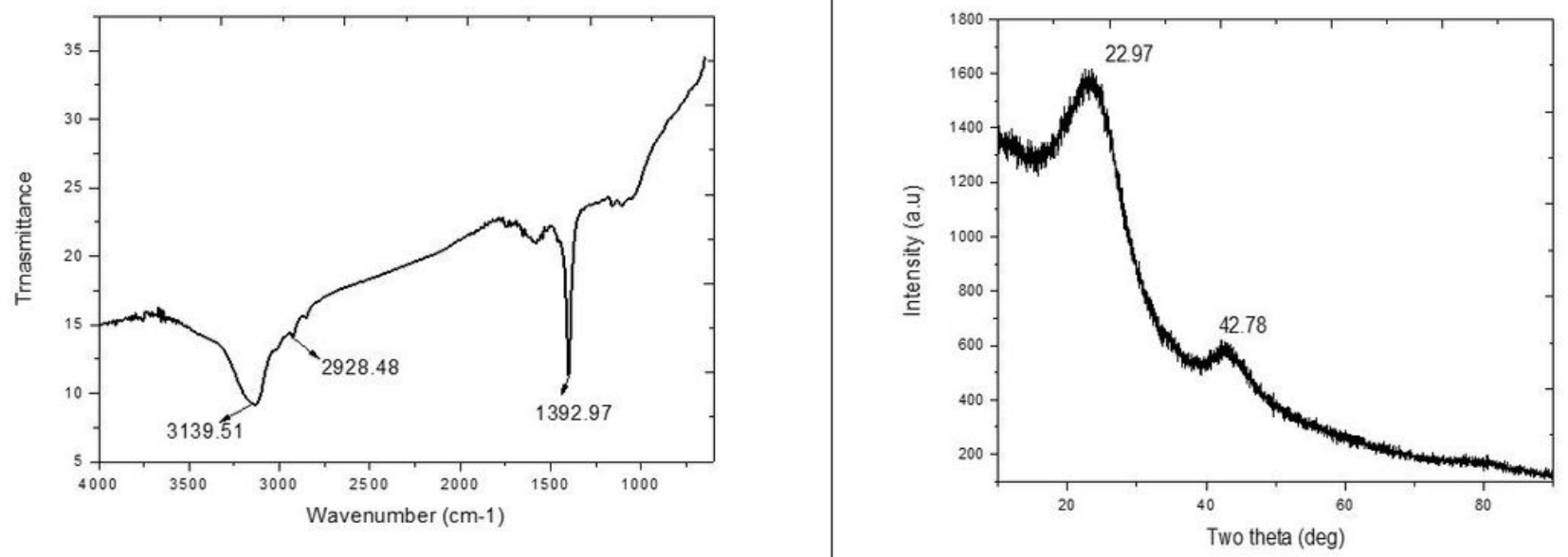

(a)

(b)

Figure 2

PET plastic mediated carbon microsphere: (a) FTIR and (b) XRD 


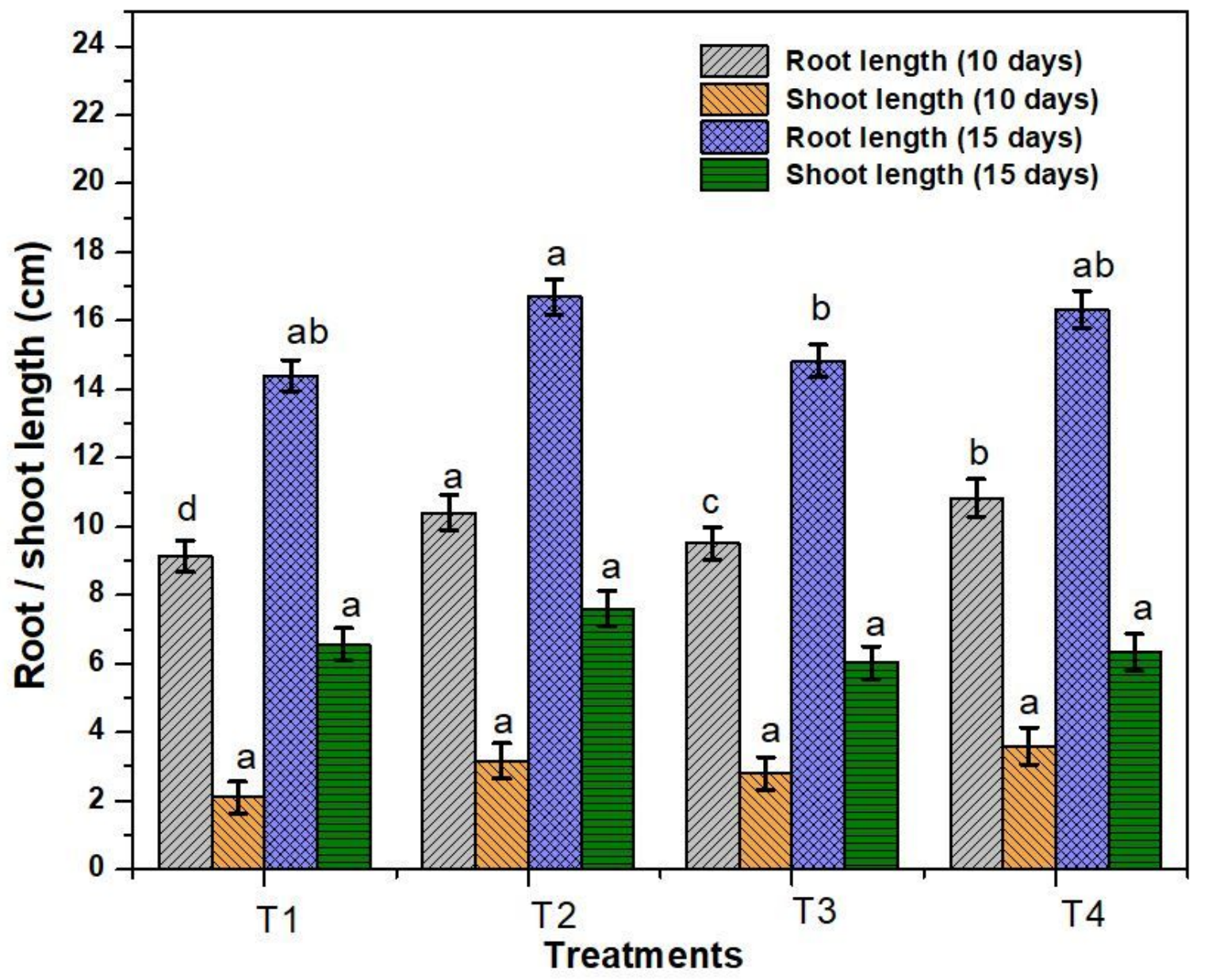

Figure 3

Parameters of the elongation percentage according to treatments with day variables. Different letters indicate significant differences at $p<0.05$ according to the Tukey-HSD. 


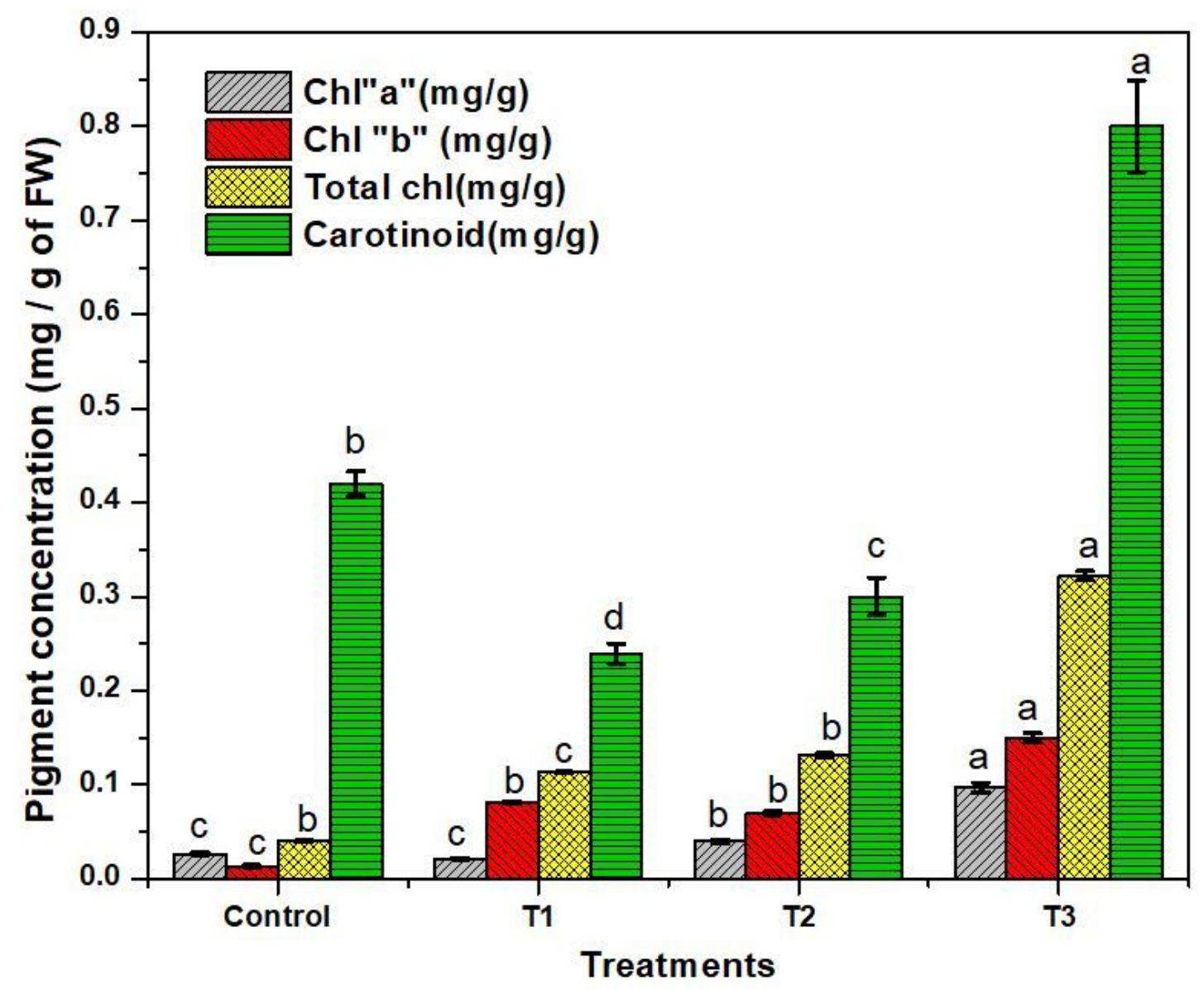

Figure 4

Biochemical analysis of pigments at treatment variables. Different letters indicate significant differences at $p<0.05$ according to the Tukey-HSD. 


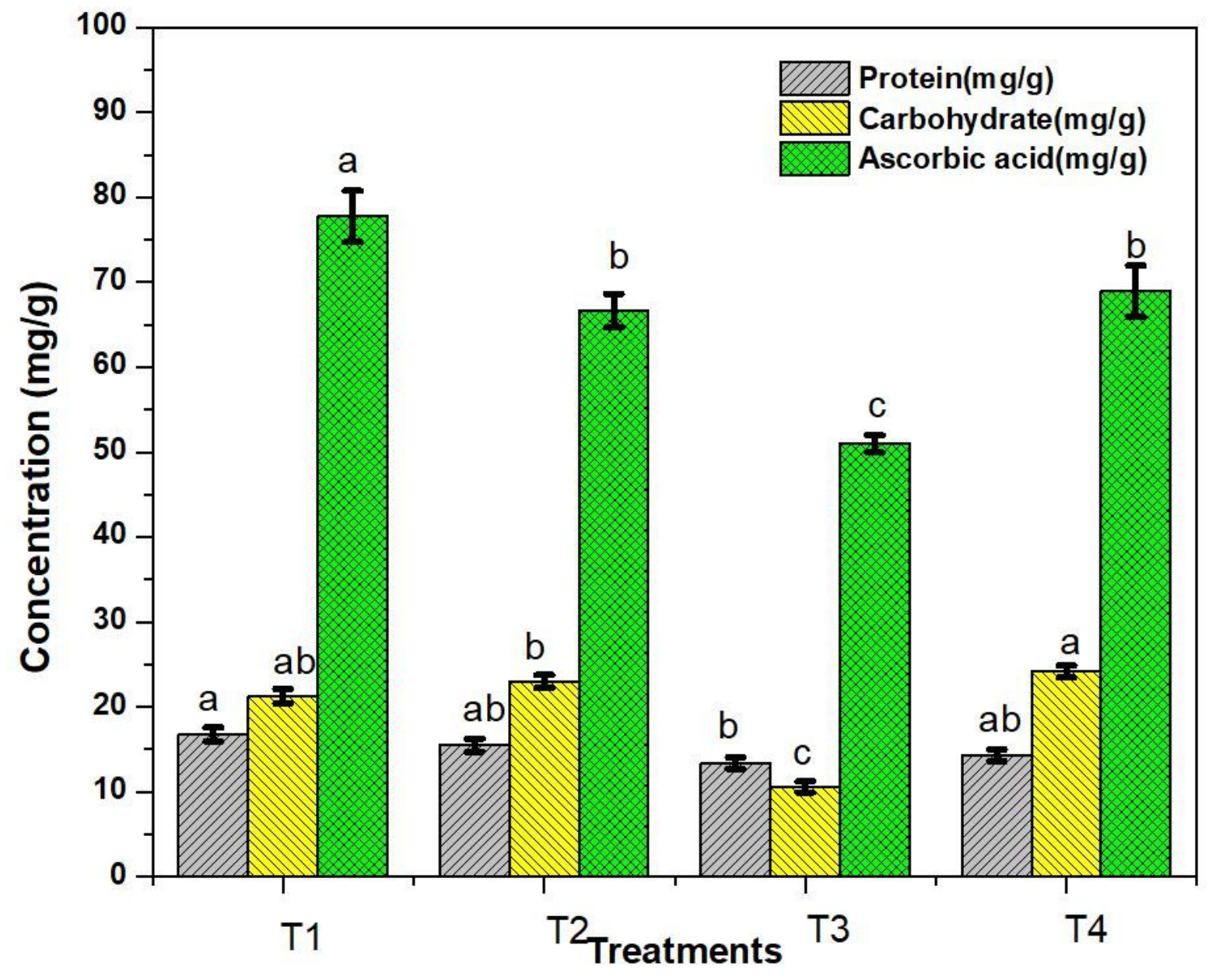

Figure 5

Biochemical analysis of protein, carbohydrate and ascorbic acid at treatment variables. Different letters indicate significant differences at $p<0.05$ according to the Tukey-HSD.

\section{Supplementary Files}

This is a list of supplementary files associated with this preprint. Click to download.

- Figsupply.docx 